\title{
The '419 Scam': An Unacceptable 'Power of the False'?
}

\author{
John Scannell, Macquarie University
}

The variations on the advance-fee fraud known as the '419 scam' are legion, but these email solicitations generally revolve around a common theme: a multi-million dollar compensation for assistance in emancipating a personal fortune out of a corrupt country. Solicitations to this effect appear in email inboxes with monotonous regularity, and while ignored by most, they remain enticing enough to fleece unwitting victims of almost $\$ 10$ billion dollars each year (Cheng 2010). These contemporary iterations of the centuries-old 'Spanish Prisoner' advance-fee fraud are commonly referred to as '419 scams' after the Nigerian criminal code for fraud (Longe \& Osofisan 2010). ${ }^{1}$ This reflects how the scam became entrenched in Nigeria during the 'Second Republic' reign of President Shehu Shagari in the 1980s. Adversely affected by the falling oil prices of the time, Shagari's presidency was marred by a period of sustained economic decline (Klitgaard 1991) where rising unemployment and escalating poverty provided the

\footnotetext{
${ }^{1}$ A detailed description of the history of the Spanish Prisoner confidence trick can be found on Wikipedia ('Spanish Prisoner' 2013). As described on the Wikipedia page the Spanish Prisoner con originates in the late 16th century and forms the basis of the contemporary 419 scam: 'In its original form, the confidence trickster tells his victim (the mark) that he is (or is in correspondence with) a wealthy person of high estate who has been imprisoned in Spain under a false identity ... Supposedly the prisoner cannot reveal his identity without serious repercussions, and is relying on a friend (the confidence trickster) to raise money to secure his release. The confidence trickster offers to let the mark put up some of the funds, with a promise that he will be financially rewarded when the prisoner returns, and perhaps also by gaining the hand of a beautiful woman represented to be the prisoner's daughter. After the mark has turned over the funds, he is informed that further difficulties have arisen and more money is needed. With such explanations, the trickster continues to press for more money until the victim is cleaned out or declines to put up more funds.'
} 
ignoble conditions that would entice an economically pressured public sector to illegally trade in the official documentation necessary to sustain this fraudulent practice (Glickman 2009: 473). As the economic instability of the 1980s pushed on into the 1990s, the rise of internet communications allowed 419 advance-fee scammers even greater capacity to ply their nefarious trade into years of exponential growth (Andrews 2006). No longer hampered by the laggard pace of the letters and faxes of old, the increased availability of computers equipped with email and email-harvesting software offered a more expedient method of performing this lucrative confidence trick.

While not without exception, the ubiquity of the 419 scam generally remains dependent on 'victims' whose avaricious intentions outweigh their better judgment. ${ }^{2}$ Nevertheless, mainstream media accounts tend to ignore this essential detail when subjecting the scammers of the developing world to scarcely concealed disdain (Today Tonight 2010; Secrets of the Scammers 2014). This is the 419 scam as moral panic, a brazen manipulation by an unscrupulous Other that is reflective of moral impropriety, lawlessness and digital dystopia. Despite the fact that most of the world's current 419related internet traffic no longer even derives from West Africa (Longe \& Osofisan 2010), the scam continues to blight Nigeria's international profile as well as that of neighbouring Ghana. ${ }^{3}$ Both countries are regularly castigated by Western media reports that conveniently overlook the fact that much of the technology used for this nefarious activity originally arrived from the West in the first place as e-waste (Frontline 2009).

\section{E-waste}

Fifty million tonnes of e-waste are generated worldwide each year (Schwarzer et al. 2005). As the sheer volume produced by the developed world exceeds the capacity of its responsible recycling, vast amounts of end-of-life equipment will eventually be exported to developing nations such as Nigeria and Ghana instead (Greenpeace 2009). If the containers of old computers were once welcomed as vital infrastructure, 'soon

\footnotetext{
${ }^{2}$ This essay is concerned with the politics of the 419 scam and the racial profiling that comes with its reporting in Western media; the essay does not discuss the vast array of scams operating throughout the internet. This includes scammers who use online dating sites to prey on the aged, lonely and vulnerable and who should be subject to the contempt they deserve. While such methods have been employed by 419 scammers, and are particularly lamentable, preying on the lonely is hardly confined to West Africans; it is an international phenomenon.

3 The report 'On the Origins of Advance Fee Fraud Electronic Mails: A Technical Investigation Using Internet Protocol Address Tracers,' determined that as a percentage of 400 emails, the breakdown of country of origin was: America and Canada 28.5 percent, Europe 23.2 percent, Africa 20.4 percent, South America 15.2 percent, Asia 9.5 percent, Australia 4.2 percent (Longe \& Osofisan 2010: 21).
} 
exporters learned to exploit the loopholes by labelling junk computers "donations" (Frontline 2009). Arriving from Europe and North America the cargo ends up dismantled as salvageable content by second-hand computer vendors, where the bulk of the electronic junk is dissembled and crudely smelted in the environmental disaster areas of Guiyu in the Guangdong province of China ('A Cadmium Lining' 2013) or Agbogbloshie in Accra, Ghana (MacDougall 2012).

Recent profiles of Agbogbloshie (Frontline 2009; Blood, Sweat and Luxuries 2012) have documented the lives of its resident child population who are sent by their families to live and work the massive e-waste dump. Using rudimentary tools, such as small stones, to break up the unwieldy remnants of the discarded computers and domestic electronics, the children light fires to melt the plastic off the cables and components in order to extract their precious metal content. Such fires burn continuously on the dumps and subject the area surrounding Agbogbloshie to a lingering haze of toxic smoke. The source of chronic respiratory infections, which are virulent enough to leave the children of the dump permanently hoarse, the smoke will eventually penetrate the entire community (MacDougall 2012). Witness to the toxic e-waste that spews from the scrap yards of developing nations, Greenpeace scientist Dr. Kevin Bridgen warns of the dangers of hazardous chemicals that affect the reproductive as well as brain and nervous systems. Of even greater concern is that most of the workers exposed to these poisonous dumps are children (Bridgen cited in Greenpeace 2008).

As part of a three-year long research project for the University of Ghana, Atiemo Sampson tested the chemical content of soils around e-waste sites and his report details how civic centres situated near them are subject to 'lead, cadmium and other healththreatening pollutants at more than 50 times normal levels'(MacDougall 2012). Vast expanses of these e-waste dependent cities are now emaciated rubbish dumps, where the by-products of this crude metal extraction contaminate the water supply and everything around it ('A Cadmium Lining' 2013).

To say that this scenario adds insult to injury is an understatement. Not only are the remnants of Western luxury dumped on the doorstep of the world's poor, but its toxic contents are left to fester in its ecosystems. While the international trafficking of hazardous e-waste from OECD to non-OECD countries was effectively banned by the Basel Convention in October 2011 ('A Cadmium Lining' 2013), the lucrative trade 
persists, although international recognition has given the governments of affected countries the legal grounds to more effectively enforce its prosecution. In January 2013, the Nigerian government imposed a \$1 million fine for the importation of "two 12-metre containers full of defunct televisions, computers, microwaves and stereos, aboard a ship from Tilbury in Britain-the fifth such incident in three years' ('A Cadmium Lining' 2013). Despite the occasional prosecution, adequate policing of this type of crime remains difficult ('A Cadmium Lining' 2013), and perhaps even unwelcome, as the very poorest communities of the developing world who extract a meagre living from the ewaste can ill-afford its redirection to another more accommodating destination.

Within the advanced capitalist economies so dependent on unrestrained consumption, the lack of recognition of its e-waste dumping in the developing world is unsurprising. So rather than simply isolate and castigate the 'out of sight, out of mind' problem of ewaste dumping in the developing world, perhaps a more pertinent strategy might be guided by the tenets of a Guattarian-style 'ecosophy' as to elevate the relational and/or transversal relations between social, mental and environmental spheres above apparently singular ecological problems. For the West to take responsibility for its poisoning of the developing world it has to be 'stung' and it has to be shown its reciprocity in this vicious cycle. As Guattari argues in The Three Ecologies, the nature of ecosophy cannot be based on a 'molar' or organized politics of consensus but rather on a dissensus that might "processually activate isolated and repressed singularities that are just turning in circles' (Guattari 2000: 51). If consensus is based on universals that produce, in this case, a sanctimonious Western subjectivity, then Guattari argues that we can only see past this narrative construction through a shift from consensual mass media to dissensual post-mass-media. In this respect, I believe that the 419 scam provides a potentially interesting example of such dissensus: while motivated by ill-will, it is also perhaps the only way for the non-West to extract its long-overdue reparations.

Convenient as it might be perceived by some, the 419 as political struggle is constitutive of the Sakawa subculture of Western Africa. As discussed in a 2011 Vice.com documentary, The Sakawa Boys, the 419 scammers known as 'Sakawa boys' in Ghana and Yahoo Boys in Nigeria utilize black magic and traditional Akan religious rituals as inherent to the online frauds and scams that mainly target foreigners (Vice.com 2011). The documentary presents excerpts of the popular Sakawa Boys series of films from 
Ghana that shows the scammers justifying their activities as payback for colonial exploitation of their resources (Vice.com 2011). Unlike previous profiles of 419 scamming by the consensual Western mass media, the Vice.com documentary did well to present the vicious cycle of iniquity that drives the Sakawa subculture. It thus highlighted how this mutual relationship between 419 scams and Western e-waste is perhaps the best way to engender a break in repressed Western subjectivities. The documentary also managed to provide a diagram of the relationships between apparently disparate events and practices as transversal pathways between ecologies, thereby engendering the type of renewed interdisciplinary critical practice that Guattari calls upon.

The adverse outcomes of e-waste dumping is not restricted to ' 419 scams' but also include more clandestine activities such as 'data mining,' the term given to the salvage of personal information that resides on the innumerable unerased hard drives so thoroughly represented among the cargo. As documented in the PBS Frontline report, Ghana: Digital Dumping Ground (2009) this destructive relationship between e-waste and fraud continues unabated as salvaged hard drives are traded at open-air markets by merchants who freely acknowledge that organized criminals comb through the drives for personal information to use in scams (Frontline 2009). Unbeknownst to the previous owners of the equipment, these drives are scanned for intimate personal data that might assist credit card fraud and identity theft (Frontline 2009), yet more evidence of how illegal dumping exposes our apparently private data to belligerent strangers. In anticipation of my reading of Deleuze and Guattari that follows, we are reminded of how easily the e-waste of Western privilege is recycled into the decentred, rhizomatic war machines of online fraud.

\section{Scambaiting}

The iniquities of systematic environmental pollution or colonial exploitation are alas barely considered by the 'scambaiting' vigilantes of the internet. Incensed by the relative success of the 419 scammers, and wilfully blind to the actual global conditions that perpetuate the fraud, 419 vigilantes or scambaiters-without exception citizens of rich Western countries - take it upon themselves to exercise what they perceive as appropriate corrective justice. Employing fake identities (usually deliberately poorly disguised English language puns); the scambaiters feign interest in 419 scam 
opportunities in order to assiduously toy with their prey. In episodes that can last for months at a stretch, the scambaiters string along their targets for as long as possible with a promise of funds that, of course, never actually transpire. Depending on their creative deviousness, some of the vigilantes will even scam the scammers; their most lauded feats include not only the reverse extraction of cash but also getting scammers to travel to secluded regions of Europe in the pursuit of fraud (419eater 2013; 'Secrets of Pickpockets, Shoplifters, Scammers' 2014). ${ }^{4}$ With each 'bait' an opportunity for a more audacious sting, the protracted correspondence between scammers and scambaiters is then diligently posted on forums such as 419 eater.com and 419 baiter.com. These sites contain photo galleries documenting the scambaiters' impressive stings, including the 'rogues' gallery' of photos requested of the scammers to verify their identity. Following the strict instructions conveyed by the scambaiters, their marks are coerced into increasingly compromising photos and situations, the more outlandish the better (mainly the holding of signs with sexual double entendres but also extending to novel gestures such as bread-based headwear). ${ }^{5}$ Under the rubric of vigilantism, the scambaiters successfully exploit the 419 moral panic for the amusement of the internet, where such malicious behaviour is defended by scambaiters as a way of keeping scammers busy and thus deter them from robbing other innocent victims and otherwise fostering organized criminal activity (419eater 2013). Stringing out the ruse for as long as possible, with appropriate photographic evidence, is the measure of scambaiting success: 'Well, put simply, you enter into a dialogue with scammers, simply to waste their time and resources. Whilst you are doing this, you will be helping to keep the scammers away from real potential victims and screwing around with the minds of deserving thieves' (419eater 2013).

Such fanciful justification is hypocritical at best and downright myopic at worst, as the scambaiters wilfully ignore the culpability of a Western economic hegemony that allow young children to live on rubbish dumps so toxic that they regularly cough up blood from respiratory illness (Blood, Sweat and Luxuries 2012). While the social and economic inequalities that inspire 419 scams are not in themselves a blanket justification for criminality, to scambait the scammers is hardly an appropriate corrective justice; one wonders what might transpire if the sheer zeal that goes into 
scambaiting, which almost borders on the pathological, might be better spent lobbying for a more productive political action. As reported in a recent Wired magazine profile on 419 baiter, 'Shiver Metimbers,' 'up to seven hours a day' is invested into his scambaiting activities (Andrews 2013).

Of course one is not so naïve as to believe that the scambaiter is in it for anything but entertainment, and despite their protestations, racist entertainment at that. The redoubtable scambaiters proudly display their 'trophy' catches on the sites, which in the case of the 419eater.com forum are signified by the pith helmets of the colonial safari (419eater 2013). Despite the overtures of colonialism and paternalism (referring to their marks, for example, as 'lads') (419eater 2013) that pervade the scambaiting sites, they continue to stringently deny any accusations of racist intent ('Trophy Room' 2013). Perhaps the remnants of colonialism are so ingrained in the Western psyche that we can actually take them at their word. Perhaps it is equally ingrained in the minds of the 419 perpetrators themselves as their fabricated tales of woe reiterate the Western stereotypes of corruption, violence and helplessness of which their countries are commonly associated. New media ecologies, same old presumptions.

Despite the questionable ethics driving the dialogue between scammer and scambaiter, this bizarre battle of wits is not entirely unproductive; at the very least, it engenders conversations between regions of the world once hardly communicating at all. To facilitate these scams, or to respond in kind with any degree of success, requires a level of engagement with the milieus that each seeks to infiltrate, a process from which springs an unprecedented 'intimacy' of communication. In the midst of the two-way deception, both scammer and scambaiter have to study the other in order to become the identities each has fabricated. The 419 vigilante as becoming-scammer, the scammer as becoming-victim. This mutual becoming requires its participants to immerse themselves in imagination, prediction, logistics, geographies, languages and customs of those environments they are attempting to breach. To pull off scams, 419 or otherwise, is precisely to make fiction of such a quality that it can no longer be discerned from the real. If ongoing global inequality is justified through constructed narratives of truth, the very type drawn upon by the scambaiters, then how might the fabulation inherent in the 419 scam turn things around? 


\section{Fabulation}

To better pursue the creative possibilities of these fabricated encounters, we might consider the concept of fabulation, which comes to us from the philosopher Gilles Deleuze via his predecessor Henri Bergson. While employed only fleetingly throughout the Deleuzean oeuvre, the concept receives its most protracted exegesis in Cinema 2: The Time-image (1989), as the 'powers of the false' (Deleuze 1989: 121). This latter concept an expression of Deleuze's sustained commentary on notions of a 'truth' underwritten by prevailing hegemonic systems of thought and differentiated from the false only by its endurance through time. In contradistinction to the ancient philosophers, for Deleuze the true and false are not eternal categories, but are differentiated by form, the true has form and iterability, while the false does not (Smith 2013: 384-385). For Deleuze, it is time that calls the form of the true into question, and his book on Cinema 2: The Time-image identifies films such as the 'documentaries' of Pierre Perrault and Jean Rouch that place traditional concepts of truth into crisis by presenting time-images that destabilize the truth and expose the false as a 'becoming as potentialization, as series of powers' (Deleuze 1989: 275). As Ronald Bogue informs us in his essay 'The Concept of Fabulation' (2010), these directors problematize veracity as a functional strategy of their respective works:

\footnotetext{
The French word recit, like the English word "story," can be used to describe both true and false accounts of events. One can tell the true story, but one can also lie by "telling stories," or creatively "make up stories" to entertain, enlighten, astonish, and so on. In the films of Perrault and Rouch, the spoken word takes on a special significance. While the visual images of the films display the becoming of time that fuses before and after in an ongoing process, the voices of the speakers engage "the pure and simple function of fabulation" as they "legend in flagrante delicto." (Bogue 2010: 31)
}

As Bogue goes on to explain, the subjects of Rouch's documentaries often collaborate with him in the invention of the films' stories, so the films fabulate as they document, challenging such concepts of 'story' to the point of indiscernibility. This point of indecision of the real and the fictive offers a new potential for thought 'beyond description and narration' (Deleuze 1989: 147).

Fabulation in its Deleuzean reinterpretation bears little resemblance to Bergson's original. In Bogue's essay 'Bergsonian Fabulation and the People to Come' (2007), we learn that fabulation is not only a comparatively recent term, but that its first philosophical use can be attributed to Bergson's final book, The Two Sources of Morality and Religion (1977 [1932]). Fabulation ('myth-making') as a Bergsonian 
concept is conceived as an essential intervention into the anti-social tendencies of intelligence, where its promotion of individual autonomy posed a fundamental threat to the social fabric. Intelligence fosters an awareness of the comparative limitations of human powers and its concepts of mortality and powerlessness induced despair (Bogue 2000: 92). It further inspired the formation of "closed societies" based on exclusion (where such exclusion is regulated by all manner of habit and custom' (Bogue 2000: 93) that served to further reiterate its anti-social tendencies (Bogue 2000: 92). According to Bergson, we turned to the fabulation of religious belief to provide a vital form of social cohesion, and to compensate for intelligence's inherently anti-social tendencies. For Bergson, the most fundamental response to the social threat posed by intelligence, is this creation of religion, the 'raison d'être of the fabulative function' (Bogue 2000: 93), where our belief systems are constitutive of a primitive instinct that undermines the veneer of rationality in the modern world (Bogue 2000: 97). The life changing hallucinations that come to us, for example, in the event of shock, are the products of fabulation's 'hallucinatory fictions - vivid, haunting images that imitate perception and induce action' (Bogue 2000: 95). Such aleatory apprehensions counteract the operations of judgment and reason: 'Fabulation, then, emerges in the shock of an event, a vertiginous moment of disorientation in which images bypass reason and work directly on the senses to induce action' (Bogue 2000: 95). This primitive will to fabulation, was for Bergson, an inherently negative phenomenon and thus separated from genuine material creation (Bogue 2000: 97).

Rather than simply dismiss it as an aberration from the real, Deleuze instead seizes fabulation as a positive power of creation. The bypassing of reason so troubling to Bergson becomes, in the hands of Deleuze, a genuinely creative process, with the 'powers of the false': 'a way of falsifying orthodox truths and fashioning new truths, with the ethical aim of fostering a people to come' (Bogue 2009: 4; Deleuze \& Guattari 1988: 345). Deleuze's commitment to the power of fabulation underscores his overturning of Platonism - to free the copy and its simulacrum from a compromised 'real' - and in the footsteps of Nietzsche, to repudiate representations of the 'true.'

In Cinema 2: The Time-image Deleuze seizes upon Orson Welles's F for Fake (1974) as a cinematic extrapolation of the creativity that emerges from the inability to discern truth from falsehood. Welles' fable recounts our investment in the false, revolving as it 
does, around the forger who will make a 'copy' to the specifications of the art dealer who, in turn, cannot tell the painting is a fake because it was produced by avoiding the mistakes that he learned from the dealer in the first place (Deleuze 1989: 146). The 'false' work, indiscernible from the real, stands for itself, in art galleries the world over. Welles' film problematises the dialectical relationship forced upon actual and virtual images, which for Deleuze are equally real, but which are generally and problematically conflated with the true and false. In the name of revoking the negativity attached to the fake, Deleuze defers to the power of Nietzschean films (Deleuze 1989: 137), such as Welles's $F$ for Fake, as evocations of the creative power that emerges when the forger destroys the certainty of 'truth' (Deleuze 1989: 137). As Deleuze says after Nietzsche, "the "true world" does not exist, and, if it did, would be inaccessible, impossible to describe, and, if it could be described, would be useless, superfluous' (Deleuze 1989: 137).

The true is functionally useless in the sense that once apprehended it is terminal. In contradistinction to truth's creative stasis, is the productive elusiveness of the false. Celebration of the false is so often witnessed in our popular culture which celebrates the 'criminal' behaviour of fakes, forgeries and fraud in the name of entertainment, and further testifies to our ambivalence to morality. The false, of course requires an audience. Confidence tricks such as the 419 scam, require a 'victim' who is just as keen on beating 'the system' (founded upon an arbitrary truth and morality), as the scammer themselves. Thus we arrive at our current state of morality where some forms of fabulation can escape judgement, and others cannot; organized religion is legal, but other forms of 'faith' are judged as deficient. Either way, the genetic reality of fabulation in its productive virtuality is beyond dispute. That is why it is not correct to conceive of the false here as the pursuit of the untrue, or existing in a dialectical relation to an established truth, but instead as will to creativity, inherent to us all:

\footnotetext{
There is no more "truth" in one life than any other: there is only becoming, descendant or ascendant, and life's becoming is "the power of the false," a noble will to power. "False" here is not opposed to the "true," but rather allied to an aesthetic or artistic will, the will to create ... it is an artistic will, the becoming of an ascendant life that creates new possibilities and experiments with new modes of existence. If becoming is the power of the false, then the good, the generous, or the noble is what raises the false to its highest creative or transformative powers - a becomingartist. (Rodowick 2010: 103)
}

To return to the discussion at hand, even if the 419 lacks nobility, it is not for nothing that we refer to its instigators as 'con-artists.' For as reprehensible as some of these 
scamming activities are, we might look beyond the reactive judgement of morality, to ask instead what connections such fabulation makes possible. Along the lines of the becoming engendered by these 'powers of the false' we might say that the 419 scammers are instigating their own transformative powers in one of the few ways currently available to them. A people to come, by any means necessary. If the creation of a people requires its conception and articulation, its presence, then it must seize whatever means it has available to territorialize. There is perhaps no moral way to do this, only to simply proceed. Lacking agency over the truth which has produced the histories of their oppression, colonialism, imperialism and now the global capitalism of e-waste, there is little other recourse than to utilize instead the powers of the 'false'. This differentiates their political position from the reactive scambaiters. As the subjects of the same advanced Western economies that dominate the social order of the globe, they are generally free to retract back into the official version of truth they produce, and the relative luxury it provides. For this reason it is important to qualify the 419 as a creation of 'minority,' even if the term under Deleuze differs from its conventional understanding.

\section{Minority}

Situational rather than numerical in nature, the concept of the minor used here is derived from Gilles Deleuze and Felix Guattari’s, Kafka: Toward a Minor Literature (1986) and elaborated in subsequent works, most notably A Thousand Plateaus (1988). The minor is not simply an identification, nor can it be represented as such, but is, instead, a 'becoming,' predisposed as it is to the majoritarian or dominant forces of social 'stratification.' Quite simply, if the majoritarian is conformity to the general state of things, then the minority is becoming 'something else.' In this sense, given that life is change, the minor culture is always better oriented to embrace this change compared to its major counterpart. Deleuze and Guattari have summarized these opposing orientations in the following way: 'we must distinguish between the majoritarian as a constant and homogeneous system; minorities as subsystems; and the minoritarian as a potential, creative and created, becoming' (Deleuze \& Guattari 1988: 105-106). As they differ from their more common understanding, the categories of major and minor should not be simply understood in quantitative terms, but instead as reflections of relative power. As Deleuze writes: 'The difference between minorities and majorities isn't their size. A minority may be bigger than a majority. What defines the majority is a model 
you have to conform to: the average European adult male city-dweller, for example ... A minority, on the other hand, has no model, it's a becoming, a process' (Deleuze 1995: 173-174).

Deleuze and Guattari offer the work of Franz Kafka as exemplary of a 'minor' literature, 'less a concern of literary history than of the people' (Bogue 2003: 93). The means of collective expression provides the conditions for the people to come, who do not find identity in the true, as hegemonic construction, but instead in the creative powers of the false: 'The task of a political literature is to contribute to the invention of this unborn people who do not yet have a language. If the people are missing, says Deleuze, it is precisely because they exist in the condition of a minority' (Smith 1997: xlii). They explain how Kafka, as a Czech Jew, would express a minority becoming by assuming a writing style that would utilize a variety of languages - the Czech vernacular, Hebrew, Prague German and Yiddish, itself a 'nomadic movement of deterritorialization that reworks German' (Deleuze \& Guattari 1986: 25), to create a way out of the strictures of linguistic domination of the majoritarian culture. Extricated from the majority, and with little capacity to constitute it, this precarious situation beckons a creativity of survival, with the minor forced into creation as a way of life. This is why a 'minor literature,' in its revolutionary capacity for fabulation will always remain apart from the major language from which it transpires. The only means available to a minor people is to fight the 'true' histories of their oppression with 'false' stories of their becoming: 'a creative storytelling that is, as it were, the obverse side of the dominant myths and fictions, an act of resistance whose political impact is immediate and inescapable, and that creates a line of flight on which a minority discourse and a people can be constituted' (1998: xlv).

The 419 scam might be similarly construed as an active resistance to the 'dominant myths and fictions' of minority oppression, founded as these stories are, upon an historical deficit of 'truth' (such as colonial history). As reflected in the burgeoning Sakawa culture, this is the most expedient method of extracting appropriate reparations, in a world where the truth, even in its apprehension, is far too complex to be understood, let alone represented. For the 'real' truth of colonialism and persecution, even if it could be articulated, would do little to alleviate the imminent material situation of the people anyway, so instead they capitalize on these 'truths' of their oppression in other more 
creative ways. As central fixtures of 419 scam emails, corruption, paternalism, superstition and scenarios of chaos transform colonial 'truths' into war machine: as 'an insect that mimics a leaf does so not to meld with the vegetable state of its surrounding milieu, but to re-enter the higher realm of predatory animal warfare on a new footing' (Massumi 1987).

If consensus is derived from the narratives of majoritarian truth, a dissensus would draw upon a necessarily minor fabulation, such as that inherent to the 419 scam. There is of course, an important caveat that must be made here. As Daniel W. Smith writes in 'Temporality and Truth', 'the falsifier is not a liar since the liar is localizable (the liar 'owns' his lies)' (2013: 386) and to pose the 419 scammer as 'minor ,' to the scambaiter's majoritarian orientation, is only due to the fact that there is little else available to the poorest sections of the developing world in which to transform their situation. In the absence of productive international dialogue, what else is there for a minority to do? In Cinema 2: The Time-image, Deleuze refers to fabulation as the 'story-telling function of the poor' (Deleuze 1989: 150), in the sense that its creative capacity might institute new modes of social organization when they have little other means available to them. It is only by operating outside the law of oppressive truths that the minor can fabulate a new existence. As Deleuze writes: 'the moment the master, or the colonizer, proclaims 'there have never been people here,' the missing people are a becoming, they invent themselves, in shanty towns and camps, or in ghettos, in new conditions of struggle to which a necessarily political art must contribute' (Deleuze 1989: 217).

Given the disparity of cultural experience between the shanty towns of the developing world and the comparative luxury of the West, one wonders whether it is only through fabulation that any conversation can start at all. When assessing the interactions of scammer and scambaiter alike, perhaps it is best to keep in mind Nietzsche's call for values beyond good and evil, where the noble and the base must be evaluated instead of being judged:

It is not a matter of judging life in the name of a higher authority which would be the good, the true; it is a matter, on the contrary, of evaluating every being, every action and passion, even every value, in relation to the life which they involve. Affect as immanent evaluation, instead of judgement as transcendent value: "I love" or "I hate" instead of "I judge." (Deleuze 1989: 141) 
To align the criminal activities of 419 scammers with such creativity, will no doubt aggravate critics as representative of moral relativism. Lest this essay appear as a simple romanticisation of the 419 scam, it is important to acknowledge that it does do some very real damage to the profile of the countries of which it is associated. The moral panic that surrounds the proliferation of the 419 , as a fraud of the developing world, is used as evidence of the pre-existing geopolitical schism between West and non-West and as a justification for its further oppression. Moral panic, which by nature places the blame on a singular cause, such as the blight of the 419 scam, deliberately overlooks a vast ecology of misdeeds that have engendered it in the first place. As vast volumes of toxic e-waste slowly make their way through the world's ecosystems, we all suffer.

Even as the scambaiters' sanctimonious vigilantism bears testament to the West's ongoing blindness to their own culpability of global iniquity, we could at least make sense of its potential for an intimacy of dialogue between disparate parts of the globe, which are ignored by the global public sphere of the news agencies. At present these correspondences necessarily require 'intercessors,' 'that is, the taking of real and nonfictional characters and putting these characters in the condition of making-fiction,' and in the cases of 419 scammer and scambaiter alike, 'the author takes a step towards his characters, but the characters take a step towards the author: double-becoming' (Deleuze 1989: 222). This double-becoming might inspire a new creation of the 'truth' that could potentially, 'break the continuities of received stories and deterministic histories, and at the same time...fashion images that are free of the entangling associations of conventional narratives and open to unspecified elaboration in the construction of a new mode of collective agency' (Bogue 2012: 106). This egalitarian scenario can only begin with the 'powers of the false.' As Deleuze has said, we only begin to think under the violence of encounter, and perhaps the encounters between 419 scammers and scambaiters is the political fabulation that he had hoped for (Deleuze 1995: 174). While the situation at hand is in every respect unacceptable, under present circumstances what else is possible?

\section{Reference List}

419 baiter 2013. Online, available: http://www.419baiter.com/ [Accessed 20 March 2013]. 419eater 2013. Online, available: http://www.419eater.com/ [Accessed 20 March 2013]. 
'A Cadmium Lining' 2013, The Economist. Online, available: http://www.economist.com/news/international/21570678-growing-mounds-electronic-scrap-canmean-profits-or-scandals-cadmium-lining-London [Accessed 20 March 2013].

Andrews, R. 2006, 'Baiters Teach Scammers a Lesson', Wired. Online, available: http://www.wired.com/techbiz/it/news/2006/08/71387 [Accessed 18 March 2013].

Basel Action Network (BAN.org). 2005, Data Left on Hard Drives. Online, available: http://www.ban.org/BANreports/10-24-05/documents/DataLeftonHardDrives.htm [Accessed 20 March 2013].

Bergson, H. 1977 [1932], The Two Sources of Morality and Religion. Trans R. A. Audra \& C. Brereton. University of Notre Dame Press, Notre Dame, IN.

Blood, Sweat and Luxuries 2012, 'Gold/Computers-Exwaste' [television program] BBC, London.

Bogue, R. 2003, Deleuze on Literature. Routledge, New York. 2007, Deleuze's Way: Essays in Transverse Ethics and Aesthetics. Ashgate, Aldershot. 2010, Deleuzian Fabulation and the Scars of History. Edinburgh University Press, Edinburgh.

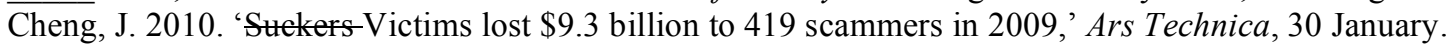
Online, available: http://arstechnica.com/security/2010/01/victims-lost-93-billion-to-419scammers-in-2009/ [Accessed 21 March 2013].

Deleuze, G. 1989, Cinema 2: The Time-image, (trans.)H. Tomlinson \& R. Galeta. Athlone Press, London. 1995, Negotiations, (trans.)M. Joughin. Columbia University Press, New York.

Deleuze, G. and Guattari, F. 1986. Kafka: Toward a Minor Literature, (trans.)D. Polan. University of Minnesota Press, Minneapolis. 1988. A Thousand Plateaus: Capitalism and Schizophrenia, (trans.)B. Massumi. Athlone Press,

Frontline 2009, Ghana: Digital Dumping Ground. PBS. Online, available: http://www.pbs.org/frontlineworld/stories/ghana804/video/video_index.html [Accessed 20 March 2013].

Glickman, H. 2005, 'The Nigerian '419' Advance Fee Scams: Prank or Peril?,' Canadian Journal of African Studies/Revue Canadienne des Études Africaines, vol. 39, no. 3: 460-489.

Greenpeace 2008, Poisoning the Poor: Electronic Waste in Ghana. Online, available: http://www.greenpeace.org/international/en/news/features/poisoning-the-poor-electroni/ [Accessed 20 March 2013]. 2009, 'Where Does E-waste End Up?' Online, available: http://www.greenpeace.org/international/en/ [Accessed 20 March 2013].

Guattari, F. 2000, The Three Ecologies. Athlone Press, London \& New Brunswick, NJ.

'John Boko' 2013, 419eater.com. Online, available: http://www.419eater.com/html/john boko.htm [Accessed 20 March 2013].

Kassner, M. 2012, 'The Truth behind Those Nigerian 419 Scammers.' Online, available: http://www.techrepublic.com/blog/it-security/the-truth-behind-those-nigerian-419-scammers/ [Accessed 20 March 2013].

Klitgaard, R. 1991, Controlling Corruption. University of California Press, Berkeley \& Los Angeles.

Longe, O. \& Osofisan, A. 2011. 'On the Origins of Advance Fee Fraud Electronic Mails: A Technical Investigation Using Internet Protocol Address Tracers,' The African Journal of Information Systems: vol. 3, no.1. Online, available: http://digitalcommons.kennesaw.edu/ajis/vol3/iss1/2/ [Accessed 18 March 2013].

MacDougall, C. 2012, 'Agbogloshie, West Africa's Biggest E-waste Dump.' Crikey. Online, available: http://www.crikey.com.au/2012/01/31/e-dump-in-agbogloshie-west-africa/ [Accessed 17 March 2013].

Massumi, B. 1987, 'Realer than Real: The Simulacrum According to Deleuze and Guattari,' Copyright, no. 1. Online, available: http://www.brianmassumi.com/textes/REALER\%20THAN\%20REAL.pdf [Accessed 21 March 2013].

Rodowick, D. N. (ed.) 2010, Afterimages of Gilles Deleuze's Film Philosophy. University of Minnesota Press, Minneapolis.

'Samuel Eze' 2013, 419eater.com. Online, available: http://www.419eater.com/html/samuel eze.htm [Accessed 20 March 2013].

Schwarzer, S., et al. 2005, 'E Waste, the Hidden Side of IT Equipment's Manufacturing and Use,' Environment Alert Bulletin, United Nations Environment Programme. Online, available: http://www.grid.unep.ch/products/3 Reports/ew_ewaste.en.pdf [Accessed 17 March 2013].

'Secrets of Pickpockets, Shoplifters, Scammers' 2014, Series 3, Episode 2 (broadcast date 2 January) [television program] Channel 4, UK. Online, available:

http://www.channel4.com/programmes/secrets-of-pickpockets-shoplifters-scammers [Accessed 12 January 2014]. 
Smith, D. W. 1997, 'Introduction. "A Life of Pure Immanence": Deleuze's "Critique et Clinique" Project,' in Gilles Deleuze, Essays Critical and Clinical, (trans.)D. W. Smith \& M.A. Greco. University of Minnesota Press, Minneapolis: xi-liv. 2013, 'Temporality and Truth,' Deleuze Studies, vol. 7, no. 3: 377-389, doi: http://dx.doi.org/10.3366/d1s.2013.0118

'Spanish Prisoner' 2013, Wikipedia. Online, available: http://en.wikipedia.org/wiki/Spanish_Prisoner [Accessed 31 March 2013].

Today Tonight 2010, 'Scam Baiter' (broadcast date 16 September 2010) [television program] Channel 7 , Perth, Australia. Online, available: http://au.news.yahoo.com/today-tonight/latest/article//7959370/scam-baiter/ [Accessed 21 March 2013].

'Trophy Room' 2013, 419eater.com. Online, available: http://www.419eater.com/html/trophy_room.htm [Accessed 20 March 2013].

Ultrascan 2010, ‘419 Advance Fee Fraud Statistics 2009,' Ultrascan. Online, available: http://www.ultrascanagi.com/public_html/html/pdf_files/419_Advance_Fee_Fraud_Statistics_2009.pdf [Accessed 17 March 2013].

Vice.com 2011, The Sakawa Boys (broadcast date 5 April 2011). Online, available: http://www.vice.com/video/mbd-vbs-the-sakawa-boys [Accessed 2 March 2013]. 